\title{
Qualidade e Monitoramento do Serviço Ambulatorial Especializado Oferecido às Pessoas Vivendo com HIV/AIDS
}

\author{
Tatiana Corrêa Ribeiro, ${ }^{1}$ Sandra Trevisan Beck, ${ }^{2}$ Amanda Borges Oliveira, ${ }^{1}$ Laura Vielmo ${ }^{1}$
}

\begin{abstract}
RESUMO
O objetivo do presente estudo foi verificar a qualidade e monitoramento do serviço ambulatorial especializado oferecido às pessoas vivendo com HIV/Aids. Foi realizado um estudo descritivo por meio da análise de dados secundários referentes a respostas ao questionário padrão Qualiaids, que busca avaliar e monitorar a organização dos serviços de saúde do SUS que acompanham o tratamento da infecção pelo HIV. O acesso ao questionário aplicado no ano de 2017 foi obtido após solicitação formal à Equipe de Pesquisa Qualiaids. Foi avaliada uma Unidade Especializada (UE) sob gestão do município e um Serviço Especializado (SE) sob gestão federal, situados em município do interior do Rio Grande do Sul. Foram verificadas as dificuldades relacionadas às três dimensões avaliativas: Gerenciamento técnico do trabalho, Disponibilidade de recursos e Organização do processo de assistência, sem ter como objetivo a comparação entre os serviços, pois estão em níveis diferentes na rede de atenção. Ambos os serviços destacaram como dificuldade gerencial o acúmulo de função e a pouca integração entre atenção básica e serviço especializado. A UE apresentou 13,9\% de faltas nas consultas médicas agendadas e o SE 19\%, com assistência satisfatória, principalmente com foco na adesão à terapia antirretroviral (Tarv), fator importante para atingir as metas nacionais 90-90-90 (diagnóstico, tratamento e supressão viral). A avaliação sistemática da adesão à Tarv, associada ao compartilhamento do cuidado, são fatores fundamentais para a integralidade da atenção à PVHIV.
\end{abstract}

Palavras-chave: HIV. Ambulatório. Assistência à saúde. Qualidade da assistência à saúde.

\section{QUALITY AND MONITORING OF THE SPECIALIZED OUTPATIENT SERVICE OFFERED TO PEOPLE LIVING WITH HIV/AIDS} ABSTRACT

The aim of the present study was to verify the quality and monitoring of the specialized outpatient service offered to people living with HIV/AIDS. A descriptive study was carried out through the analysis of secondary data related to responses to the standard questionnaire Qualiaids, which seeks to evaluate and monitor the organization of SUS health services that accompany the treatment of HIV infection. Access to the questionnaire applied in 2017 was obtained after a formal request to the Qualiaids Research Team. A Specialized Unit (UE) under the management of the municipality and a Specialized Service (SE) under federal management were evaluated, located in a municipality in the interior of Rio Grande do Sul. The difficulties related to the three evaluation dimensions were verified: Technical management of work, Availability of resources and organization of the assistance process, without having the objective of comparing the services, as they are at different levels in the care network. Both services highlighted as a managerial difficulty the accumulation of function and the little integration between primary care and specialized service. The US presented $13.9 \%$ of absences in the scheduled medical consultations and the SS 19\%, with satisfactory assistance, mainly in relation to adherence to antiretroviral therapy (ART), an important factor to achieve national goals 90-90-90 (diagnosis, treatment and viral suppression). The systematic assessment of adherence to ART associated with the sharing of care are fundamental factors for comprehensive care for PLHIV

Keywords: HIV. Ambulatory care. Quality. Health Care. Quality of Health Care.

RECEBIDO EM: 31/1/2020

MODIFICAÇÕES SOLICITADAS EM: 29/4/2020

ACEITO EM: 8/6/2020

\footnotetext{
Universidade Federal de Santa Maria - UFSM. Santa Maria/RS, Brasil.

${ }^{2}$ Autora correspondente. Universidade Federal de Santa Maria - UFSM. Av. Roraima, n. 1000, Cidade Universitária - Camobi. Santa Maria/RS, Brasil. CEP 97105-900. http://lattes.cnpq.br/4435727183593265. https://orcid.org/0000-0002-0793-766X. stbeck.beck@gmail.com
} 


\section{INTRODUÇÃO}

O advento da Terapia Antirretroviral (Tarv) e a ampliação da distribuição gratuita da Tarv pelo Sistema Único de Saúde (SUS) por intermédio da Lei 9.313 em 1996 (BRASIL, 1996), proporcionou uma mudança no perfil da infecção pelo HIV que assumiu características de doença crônica. A criação de políticas públicas de saúde para HIV foi uma resposta à forte pressão exercida pelos movimentos sociais, que exigiam ações tanto no plano da atenção à saúde quanto na prevenção e no combate às situações de discriminação dirigidas aos grupos mais afetados e às pessoas vivendo com HIV e Aids (SOUZA et al., 2010). Além disso, a disponibilidade de novos Antirretrovirais (ARV) com melhor perfil farmacológico contribuiu para o aumento da qualidade de vida das Pessoas Vivendo com HIV (PVHIV) (BRASIL, 2007).

A dispensação da Tarv ocorre por meio das Unidades Dispensadoras de Medicamentos (UDM). É pelo Sistema de Controle Logístico de Medicamentos (Siclom), estabelecido nas UDMs, que o Departamento de Vigilância, Prevenção e Controle de Infecções Sexualmente Transmissíveis (IST), do HIV/Aids e das Hepatites Virais, se mantém atualizado em relação ao fornecimento de medicamentos aos pacientes em Tarv (BRASIL, 2018). O Siclom também é uma ferramenta importante para o planejamento dos pedidos mensais de ARV, controle da dispensação de ARV e planejamento das ações assistenciais da UDM.

O Programa Brasileiro de Doenças Sexualmente Transmissíveis (DST)/Aids, que tem como objetivo principal prestar atendimento integral e de qualidade as PVHIV, por meio de equipe multidisciplinar com utilização de protocolos clínicos e terapêuticos, criou os Serviços Ambulatoriais Especializados (SAEs). Atualmente, existem 692 SAEs no Brasil, conforme informação do site do Departamento de Vigilância, Prevenção e Controle de Infecções Sexualmente Transmissíveis (IST), do HIV/Aids e das Hepatites Virais (BRASIL, 2019a). Estes serviços são unidades isoladas e possuem características institucionais e de infraestrutura heterogêneas, e os estudos mostram que a qualidade dos serviços prestados nas diferentes unidades do país é altamente variável (BRASIL, 2018; MAGNABOSCO, 2018; MELCHIOR et al., 2006; MENEZES et al., 2019).

$A$ atenção à PVHIV não é, nem deve ser, desenvolvida exclusivamente nos SAEs. Os ambulatórios especializados, vinculados ou não a hospitais, e os servi- ços de atenção básica, representam uma importante parcela dos estabelecimentos que prestam assistência à PVHIV (BRASIL, 2014, 2018; LOCH et al., 2018).

Com a expansão dos serviços especializados e o aumento dos casos de HIV/Aids, tornou-se necessário avaliar e monitorar a qualidade assistencial oferecida por esses serviços. No Brasil, em 2018, foram diagnosticados 43.941 novos casos de HIV e 37.161 casos de Aids. Entre 2012 e 2018 houve uma redução de 16,8\% na taxa de detecção de Aids, principalmente em razão da recomendação do tratamento para todos os soropositivos, independente de critérios imunológicos, instituída em dezembro de 2013 (BRASIL, 2019b), justificando os 1.096 serviços do SUS, cadastrados no Ministério da Saúde, que fazem seguimento em nível ambulatorial à PVHIV. É dessa rede assistencial, que opera o acesso universal ao tratamento ARV - pilar da resposta brasileira à Aids -, que se espera desempenho suficiente para impactar positivamente no cumprimento da meta internacional 90-90-90, a qual objetiva, até o ano de 2020 , ter $90 \%$ das PVHIVs diagnosticadas, $90 \%$ das PVHIVs diagnosticadas em tratamento e $90 \%$ das PVHIVs em tratamento apresentando supressão viral (BRASIL, 2017, LOCH et al., 2018, BRASIL, 2019). A primeira avaliação sistematizada da organização da assistência desses serviços ocorreu em 2001/2002, abrangendo 322 serviços, localizados em sete Estados brasileiros (NEMES et al., 2004), utilizando instrumento pré-validado (Qualiaids), e continuou sendo aplicado para contínua avaliação dos serviços nos últimos anos. O questionário busca espelhar a realidade da qualidade do trabalho realizado nestes serviços, e, para tanto, é constantemente aprimorado. Trata-se de uma importante ferramenta para que os serviços reflitam e aperfeiçoem suas práticas na atenção à PVHIV, além de permitir uma visão ampliada da qualidade da assistência em âmbito nacional, visando a atingir os resultados esperados no prazo estipulado (NEMES et al., 2015).

O objetivo do presente estudo foi verificar a qualidade e monitoramento do serviço ambulatorial especializado oferecido às PVHIVs, que se justifica pela relevância na área de qualidade, política e planejamento das ações em saúde voltadas para o HIV/Aids.

\section{METODOLOGIA}

Trata-se de um estudo descritivo baseado na análise de dados secundários, utilizando estatística descritiva simples. Foram verificadas respostas dadas ao Questionário Qualiaids no ano de 2017, relacionadas a dois serviços do SUS que, somados, prestam atendimento a 1.813 PVHIVs. Estes serviços estão localizados 
em município com 261.031 habitantes de acordo com o último censo (2010), e população atual estimada de 283.677 (IBGE, 2020), situado no interior do Rio Grande do Sul, e serão identificados como Unidade Especializada (UE) aquela sob gestão do município, e Serviço Especializado (SE) aquele sob gestão federal, vinculado a um Hospital Universitário. A UE identifica-se como um ambulatório exclusivo de assistência especializada a pacientes com HIV/Aids, IST e hepatites virais subordinado à Secretaria Municipal de Saúde, não incluindo crianças e gestantes. O SE caracteriza-se como um ambulatório especializado em moléstias infecciosas, estando subordinado a uma universidade pública federal.

A Equipe de Pesquisa Qualiaids, sob a coordenação da professora Maria Ines Battistella Nemes, do Departamento de Medicina Preventiva da Faculdade de Medicina da Universidade de São Paulo, desenvolveu o Sistema Qualiaids. O sistema tem sido aplicado em parceria com a gestão federal do programa brasileiro de HIV/Aids, e busca avaliar e monitorar a organização dos serviços de saúde do SUS que acompanham o tratamento da infecção pelo HIV (NEMES, 2017). Esta avaliação é realizada mediante um questionário que contém 82 questões de múltipla escolha, que englobam três dimensões avaliativas: Gerenciamento técnico do trabalho, Disponibilidade de recursos e Organização do processo de assistência. $O$ questionário é respondido em sistema on-line pelo responsável técnico do serviço, e as questões admitem resposta única ou múltipla (USP, 2019).

$\mathrm{O}$ acesso aos dados referentes às respostas dos serviços UE e SE do questionário aplicado no ano de 2017, foi obtido após solicitação formal à Equipe de Pesquisa Qualiaids. Desta forma, verificando as respostas relacionadas a cada dimensão, foram evidenciados os aspectos indicados como sendo os de maior dificuldade entre os indicadores referentes ao gerenciamento técnico do trabalho, disponibilidade de recursos e organização do processo de assistência, descartando a comparação entre serviços, pois estão em níveis diferentes na rede de atenção.

O estudo foi aprovado pelo Comitê de Ética em Pesquisa com seres humanos da Universidade Federal de Santa Maria - RS sob parecer número 2.766.330/2018, CAAE 93464418.6.0000.5346.

\section{RESULTADOS}

\section{Caracterização dos serviços e disponibilidade de recursos}

Em razão das diferenças estruturais dos dois serviços, o número de pacientes atendidos e acompanhados apresenta um quantitativo diferenciado
(Tabela 1 e Tabela 2). O município possui apenas uma UDM para dispensação de Tarv, que está situada no SE. A UDM possui um farmacêutico pertencente ao quadro funcional do Hospital Universitário e dois residentes farmacêuticos que auxiliam nas atividades. Entre as atividades desenvolvidas estão o controle dos estoques de ARV, dispensação e atenção farmacêutica à PVHIV e busca ativa de crianças, adolescentes e gestantes faltosos. Esta UDM, além de atender ambos os serviços (SE e UE), recebe usuários provenientes de consultórios particulares bem como de outros $30 \mathrm{mu}$ nicípios da mesma Coordenadoria Regional de Saúde. O dado disponível do SE, que se refere aos 1.813 usuários ativos na UDM, compreende os usuários em Tarv de ambos os serviços (SE e UE) (Tabela 2).

Tabela 1 - Quantitativo pontual de agendamentos, faltas e atendimentos mensais* nos serviços públicos que acompanham PVHIV no município de Santa Maria - RS (2017)

\begin{tabular}{lcc}
\hline & \multicolumn{2}{c}{$\begin{array}{c}\text { Serviço de acompanhamento } \\
\text { PVHIV** }\end{array}$} \\
\hline \multicolumn{1}{c}{ Quantitativo mensal } & $\begin{array}{c}\text { Unidade } \\
\text { Especializada }\end{array}$ & $\begin{array}{c}\text { Serviço } \\
\text { Especializado }\end{array}$ \\
\hline $\begin{array}{l}\text { Número total de pacientes } \\
\text { com HIV/Aids agendados para } \\
\text { consulta médica }\end{array}$ & 180 & 420 \\
\hline $\begin{array}{l}\text { Número total de pacientes } \\
\text { com HIV/Aids que faltaram às } \\
\text { consultas médicas agendadas }\end{array}$ & 25 & 80 \\
\hline $\begin{array}{l}\text { Número de consultas de HIV/ } \\
\text { Aids }\end{array}$ & 155 & 340 \\
\hline
\end{tabular}

* Dados referentes ao mês anterior à aplicação do questionário. ** PVHIV: Pessoas Vivendo com HIV.

$$
\text { Fonte: As autoras. }
$$

Tabela 2 - Quantitativo de PVHIV acompanhados pelos serviços públicos que atendem PVHIV no município de Santa Maria - RS (2017)

Número de PVHIV* no serviço de acompanhamento

\begin{tabular}{lcc}
\hline Variável & $\begin{array}{c}\text { Unidade } \\
\text { Especializada }\end{array}$ & $\begin{array}{c}\text { Serviço } \\
\text { Especializado }\end{array}$ \\
\hline Com HIV/Aids & 1024 & $1813^{* *}$ \\
\hline $\begin{array}{l}\text { HIV/Aids transferidos } \\
\text { do serviço no último } \\
\text { ano }\end{array}$ & 3 & $25^{* *}$ \\
\hline
\end{tabular}

* PVHIV: Pessoas Vivendo com HIV.

** Registro apenas dos usuários HIV em TARV.

Fonte: As autoras. 
O SE está localizado dentro de um hospital universitário e tem sua equipe ambulatorial constituída por médicos infectologistas e farmacêuticos, havendo atendimento de forma matricial por outras classes profissionais. Apesar da ausência de outras categorias profissionais, o ambulatório de doenças infecciosas conta com o suporte da equipe da Residência Multiprofissional vinculada ao hospital, que oferece atendimento sistemático em ambulatório específico com foco na adesão ao tratamento ARV. Possui disponível consultórios médicos, salas para atendimentos de enfermagem e salas para atendimento individual por outros profissionais de nível superior. A UE tem consultórios médicos e salas para atendimentos de enfermagem, não possuindo adaptações necessárias para facilitar o acesso e a circulação. Para o acompanhamento dos pacientes com HIV/Aids, ambos os serviços dispõem de médicos infectologistas, porém nenhum serviço dispõe de dentista, fonoaudiólogo, fisioterapeuta, terapeuta ocupacional e educador físico, havendo carência de outras classes profissionais que atendem pacientes com HIV/Aids em ambos os serviços (Tabela 3).

Tabela 3 - Quantitativo de profissionais que realizam o acompanhamento dos pacientes com HIV/Aids nos serviços públicos do município (ano 2017)

\begin{tabular}{lcc}
\hline & \multicolumn{2}{c}{$\begin{array}{c}\text { Serviço de acompanhamento } \\
\text { PVHIV* }\end{array}$} \\
\hline Especialidades & $\begin{array}{c}\text { Unidade } \\
\text { Especializada }\end{array}$ & $\begin{array}{c}\text { Serviço } \\
\text { Especializado }\end{array}$ \\
\hline Infectologistas & 2 & 3 \\
\hline $\begin{array}{l}\text { Médicos residentes que } \\
\text { realizam o acompanhamento } \\
\text { de rotina }\end{array}$ & 0 & 6 \\
\hline $\begin{array}{l}\text { Enfermeiro } \\
\text { Auxiliar ou técnico de } \\
\text { enfermagem }\end{array}$ & 1 & 0 \\
\hline Psicólogo & 1 & 0 \\
\hline Farmacêutico & 1 & 0 \\
\hline Assistente Social & 1 (não & 1 \\
\hline Nutricionista & 1 & 0 \\
\hline
\end{tabular}

* PVHIV: Pessoas Vivendo com HIV.

Fonte: As autoras.

Para 43,75\% dos exames citados no Qualiaids, ambos os serviços têm igualdade no tempo de disponibilização dos exames laboratoriais de rotina na avaliação inicial, principalmente determinação de carga viral, contagem de linfócitos CD4+ e seguimento relacionado ao aspecto clínico em geral. $O$ acesso a exames especializados é satisfatório no $\mathrm{SE}$, que possui indisponibilidade apenas para biópsia e elastografia hepática. A UE apresentou maior dificuldade de acesso a especialidades médicas $(70,6 \%)$ e exames para diagnóstico e seguimento de intercorrências e comorbidades $(66,7 \%)$.

Em relação à profilaxia à exposição ao HIV, nenhum dos serviços pesquisados realiza a Profilaxia Pré-exposição Sexual (PReP). A UE presta apenas seguimento aos indivíduos que recebem a Profilaxia Pós-Exposição (PEP).

\section{Gerenciamento técnico do trabalho}

O acúmulo de função foi citado pelos dois serviços como uma das dificuldades gerenciais pontuadas nos últimos seis meses. Na UE, as ações e atividades de coordenação técnica da equipe são feitas pelo mesmo profissional que realiza as funções de coordenação técnica e administrativa da equipe (controle de faltas, férias, alocação e contratação de pessoal). No SE não há um profissional responsável pela coordenação técnica da assistência ambulatorial aos pacientes com HIV/Aids (mesmo que informalmente). Nenhum dos serviços realiza avaliação das atividades de atenção à assistência em HIV/Aids de forma sistemática, com pouca participação dos profissionais em programas de capacitação. No SE o farmacêutico foi o profissional que participou de algum tipo de capacitação em 2017.

\section{Organização do processo de assistência}

$\mathrm{Na}$ UE, a primeira consulta médica ocorre em torno de 1-2 meses após o primeiro atendimento, diferente do $\mathrm{SE}$, quando o primeiro atendimento sempre inclui a primeira consulta médica. $\mathrm{Em}$ ambos os serviços aguarda-se o retorno espontâneo após o diagnóstico de sorologia positiva para HIV. Após o início ou troca do esquema de Tarv, há nova consulta com o médico ou outro profissional de saúde, com intervalo de 15 dias para o serviço UE e sete dias para o serviço SE.

A adesão ao tratamento ARV pode ser verificada por meio de diferentes estratégias. No SE são realizados serviços de checagem de rotina em todos os atendimentos (consulta médica e atendimentos de outros profissionais) e identificação da existência de dificuldades diárias, principalmente relacionadas à ingestão da medicação. Quando necessário, o SE solicita retornos para consultas médicas em intervalos menores, encaminhamento para consulta e orientação indi- 
vidual com psicólogo, assistente social ou farmacêutico, esclarecendo a importância da adesão. Havendo necessidade, a UDM no momento da dispensação dos $A R V$, pode indicar para tratamento diretamente observado ou supervisionado, oferecer porta-pílulas e/ ou tabelas e mapas de dose, bem como avaliação da necessidade e possibilidade de mudança do esquema posológico, por meio de um atendimento farmacêutico individualizado. Não havendo comparecimento à consulta clínica, o SE aguarda retorno espontâneo em todos os casos. $\mathrm{Na}$ eu, a adesão é verificada predominantemente pelo acompanhamento das oscilações nas determinações laboratoriais do nível de linfócitos CD4+ e carga viral HIV. Pacientes identificados com dificuldade no tratamento ARV recebem reforço da importância da adesão nas consultas médicas. Nos casos de falta ao atendimento agendado, a UE entra em contato em situações específicas (exames alterados, maior gravidade clínica, tuberculose, gestante e abandono).

Na UE, os casos de coinfecção HIV/Aids/tuberculose são tratados em serviços distintos. No SE o tratamento desta coinfecção é feito no mesmo local. Atividades em parceria com os serviços de atenção básica são ausentes nos dois serviços, sendo o tratamento supervisionado compartilhado de tuberculose (realizada no serviço UE) a única ação identificada com a pergunta específica sobre este aspecto.

\section{DISCUSSÃO}

A integralidade das ações de saúde depende da qualidade das diferentes dimensões do trabalho. A interação entre os sujeitos, a organização do trabaIho, o exercício da interdisciplinaridade, presente no trabalho em equipe, e a contínua incorporação de novos saberes e práticas às ações de saúde, compõem a complexidade tecnológica realizada no momento assistencial (NEMES et al., 2004). Esses aspectos precisam ser avaliados de forma integrada e contínua, pois não são estáticos no tempo e a qualidade global do serviço depende de uma harmoniosa combinação entre eles.

Independentemente das características institucionais e locais, todos os serviços deveriam possuir condições de disponibilidade de recursos, organização da assistência e gerenciamento técnico que permitam um cuidado de qualidade aceitável. A qualidade da assistência prestada nos serviços de saúde é a principal estratégia para a redução da mortalidade e morbidade relacionada à Aids, em conjunto com o diagnóstico precoce (BRASIL, 2008).
Ambos os serviços avaliados neste estudo se caracterizam como de grande porte (mais de 500 pacientes em acompanhamento). Na região sul e sudeste do Brasil $42 \%$ dos serviços caracterizam-se dentro deste porte, o qual também caracteriza a maior parte dos serviços brasileiros (LOCH et al., 2018). Existe um paradoxo entre a influência do porte do serviço na qualidade da assistência. De um lado o pressuposto de que serviços menores e menos complexos não são compatíveis com boa qualidade na atenção e de outro a possibilidade de oferta de uma atenção diferenciada e quase personalizada que é inviável para grandes serviços (BACCARINI, 2011).

Quanto à disponibilidade de profissionais nos serviços avaliados, observa-se que o serviço caracterizado como SE apresenta uma maior oferta multiprofissional vinculada ao serviço, disponíveis rotineiramente ao atendimento da PVHIV, o que permite uma maior integralidade do cuidado à PVHIV neste serviço. Em ambos os serviços avaliados, quando há necessidade de outro profissional que não está disponível diretamente no serviço, o usuário é encaminhado para outro ponto da rede municipal de saúde. Apesar do SE estar inserido em um hospital com grande diversidade de profissionais atuantes, não se observa maior facilidade no acesso a estes profissionais em razão das questões regulatórias dos encaminhamentos. Em estudo recente sobre o cuidado à pessoa com HIV/Aids na atenção primária à saúde, é relatado que o discurso mais presente nas falas dos entrevistados foi a inexistência de um fluxo formal para o acompanhamento das PVHAs na atenção primária à saúde, fazendo com que o cuidado seja realizado de forma individualizada e específica para cada caso (COLAÇO et al., 2019).

Isso, entretanto, não deve ser visto como um impeditivo para o estabelecimento de fluxos ágeis e claros de referência e contrarreferência. $O$ funcionamento em rede é fundamental para proporcionar integralidade na atenção, e o fortalecimento dos serviços especializados se dá à medida que se integram às redes de atenção à saúde do município (BACCARINI, 2011).

A atuação da residência, tanto médica quanto multiprofissional, é um importante aspecto a ser considerado no SE. Estes profissionais residentes compõem uma parcela importante das ações desenvolvidas neste serviço. $O$ ambulatório multiprofissional desempenha um papel importante no acolhimento das diversas demandas de cada sujeito e influencia positivamente na construção do vínculo usuário-serviço e, consequentemente, na adesão à Tarv (CANCIAN, 2015). 
A PReP foi disponibilizada no Brasil no ano de 2017, e sua oferta, conforme informado pela página virtual do Departamento de Doenças de Condições Crônicas e Infecções Sexualmente Transmissíveis, está ocorrendo em 16 municípios do Estado do Rio Grande do Sul, disponibilizada na capital do Estado por cinco serviços de saúde do SUS até o presente momento. Apesar de a PReP não ser indicada para todos, ela é uma opção para as pessoas que tenham maior chance de entrar em contato com o HIV, como homens que fazem sexo com homens, pessoas trans e trabaIhadores do sexo. Uma dificuldade existente para a efetivação da PReP é a capacidade do sistema em assumir o acompanhamento destes usuários durante a utilização da PrEP, pois, além da adesão ao tratamento, existe a necessidade de exames laboratoriais para monitoramento da qualidade de saúde e testagem periódica para o HIV, que tem por objetivo verificar se estes indivíduos continuam soronegativos (MAKSUD; FERNANDES; FILGUEIRAS, 2015), sendo esta precaução nem sempre aceita pelos usuários (PINKERTON; HOLTGRAVE; GALLETLY, 2008).

Tanto a PReP quanto a PEP são importantes estratégias de prevenção ao HIV. Para que haja uma boa efetividade destas ações é necessário que os gestores consigam organizar os processos de trabalho para divulgação e instituição destas estratégias de prevenção, sem, com isto, diminuir o uso do preservativo (ABIA, 2011).

O fluxo da PEP constituído no município em estudo, justifica a não prescrição da PEP na UE, uma vez que é pactuado no município que a avaliação médica e a prescrição serão realizadas diretamente em Unidades de Pronto-Atendimentos específicos, e o seguimento será feito na unidade especializada, sendo a disponibilidade de recursos na rede de assistência dependente da sua fonte de financiamento (BRASIL, 2018). Avaliações nos serviços ambulatoriais brasileiros evidenciam que a grande maioria dos serviços relata suprimento contínuo somente dos recursos de provisão do nível federal, o que corrobora as maiores dificuldades gerenciais observadas na UE (de provisão municipal) do que no SE (de provisão federal) ( $\mathrm{LOCH}$ et al., 2018). Em relação ao provimento de medicamentos ARV e para infecções oportunistas, contudo, observou-se, no presente estudo, que dificuldades relatadas pelo SE não foram identificadas pela UE. Isto ocorreu em razão de a UDM estar vinculada ao SE. Desta forma, as ações cotidianas realizadas pela UDM por intermédio de um bom gerenciamento, fazem com que as irregularidades de abastecimento de medicamentos não sejam percebidas pelos demais serviços e PVHIVs. O monitoramento dos processos e resultados do trabalho é atividade típica gerencial que instrumentaliza intervenções no sentido de tornar as ações mais efetivas, integradas e coerentes com os compromissos técnicos e éticos assumidos pelo serviço (MELCHIOR et al., 2006).

Ambos os serviços demonstram fragilidades importantes relacionadas à falta de coordenação técnica e à ausência de avaliações das atividades assistenciais. As avaliações prévias, realizadas por meio da pesquisa Qualiaids, têm mostrado piores níveis de qualidade dos serviços no que se refere ao aspecto da gerência. Estes resultados apontam para a necessidade de programar ações de forma a melhorar o gerenciamento desses serviços (BACCARINI, 2011). Neste sentido, a participação de profissionais em capacitações é importante, principalmente porque os protocolos elaborados pelo Departamento de Vigilância, Prevenção e Controle de IST, do HIV/Aids e das Hepatites Virais, são constantemente atualizados (BRASIL, 2019a). Nos serviços avaliados, a participação em programas de capacitação somente ocorreu com o profissional farmacêutico do SE, entretanto esse processo deve acontecer com todos os profissionais envolvidos na assistência à PVHIV. Embora os protocolos sejam veiculados de forma que todos os profissionais tenham acesso, a ampla discussão e socialização destas informações são importantes para a qualidade da assistência prestada.

Esta assistência deve ser eficiente para que ocorra retenção do paciente no serviço, com realização de exames e/ou retirada dos medicamentos ARV sistematicamente, sem faltar às consultas (BRASIL, 2018). A UE apresentou $13,9 \%$ de faltas nas consultas médicas agendadas, e o SE 19\%. Esses índices indicam que ainda existe dificuldade de retenção dos pacientes nos serviços de saúde. Ainda que estes valores representem uma porcentagem pequena em relação ao total de pacientes retidos, esses usuários representam um gargalo importante para o não cumprimento das metas nacionais 90-90-90 (BRASIL, 2017). Avaliações realizadas em 2007 e 2010 evidenciaram que, dentre os serviços brasileiros que realizam de alguma forma a convocação dos pacientes que faltam à consulta médica agendada, a minoria convoca todos os pacientes faltosos (LOCH et al., 2018). Este é fator preocupante, uma vez que a falta às consultas médicas de seguimento é um fator preditor da não adesão, e o fortalecimento da busca do paciente faltoso no primeiro ano de seguimento pode diminuir a morbidade relacionada a estes pacientes, reengajá-los no cuidado e meIhorar a retenção deles no serviço. No Brasil, o agendamento de consultas em até 15 dias após o início da 
Tarv, foi mantido em apenas pouco mais da metade dos serviços avaliados em 2010 (LOCH, et al., 2018). Os serviços avaliados neste estudo encontram-se atendendo plenamente às expectativas deste critério.

Outro aspecto crucial é o acompanhamento semanal após a introdução da Tarv, até que haja adaptação na vida do paciente, em razão da importância do estabelecimento de uma relação de confiança, respeito e corresponsabilidade entre a equipe de saúde e o paciente, a fim de assegurar a adesão ao serviço e ao tratamento. A má adesão é considerada multifatorial, podendo ocorrer por fatores psicossociais, como depressão, uso de substâncias psicoativas, dificuldade de acesso e comorbidades, e fatores relacionados aos medicamentos, como efeitos adversos e posologia complexa. Fatores psicossociais são monitorados pelos dois serviços mediante a atuação multiprofissional, embora não se encontrem pontuados no questionário analisado. Desta forma, a adesão à Tarv deve ser constantemente avaliada para evitar a resistência viral adquirida (BRASIL, 2018).

No presente estudo ambos os serviços utilizam estratégias para identificar os casos de má adesão, e realizam ações específicas para auxiliar a PVHIV. A ausência de UDM na UE, contudo, é fator preditor negativo de adesão, pois dificulta o acesso deste indivíduo ao tratamento e exige que o usuário acesse outro serviço para retirar seus medicamentos, os quais devem ser ofertados de forma imediata e contínua. Além disso, cria uma sobrecarga no SE dificultando a oferta de uma atenção farmacêutica diferenciada e personalizada para todos os usuários deste serviço, ação que comprovadamente fortalece a adesão ao tratamento (RODRIGUES et al., 2015). Cabe aos serviços buscar mecanismos que removam barreiras de acesso à Tarv sem prejuízo na qualidade da dispensação de ARV. Apesar das dificuldades observadas, a existência de uma UDM no município é considerada positiva, uma vez que muitos municípios ainda não possuem este serviço disponível (BRASIL, 2010), o qual deve, na medida do possível, trabalhar integrado com a Atenção Básica.

O Departamento de Vigilância, Prevenção e Controle das IST, do HIV/Aids e das Hepatites Virais, tem buscado estabelecer estratégias para promover a gestão compartilhada da atenção às PVHIVs entre os serviços especializados e a Atenção Básica (BRASIL, 2018), visando a romper com o afastamento dos serviços, ação importante tanto para profissionais quanto para pacientes. A maioria dos profissionais de saúde reconhece a importância de integração entre atenção básica e serviço especializado, porém referem dificul- dades operacionais para pô-la em prática (MEDEIROS et al., 2016), como verificado no presente estudo, uma vez que atividades em parceria com os serviços de atenção básica são indicadas como precárias tanto pela UE quanto pelo SE.

\section{CONCLUSÃO}

A avaliação da qualidade e o monitoramento do serviço ambulatorial especializado oferecido às PVHIVs, permitiram compreender as dificuldades e potencialidades dos serviços especializados que assistem PVHIVs no município, evidenciando a necessidade de melhorar a composição de uma equipe específica para $\mathrm{o}$ atendimento às PVHIVs. Em relação os aspectos relacionados à assistência direta ao usuário, foi mostrado um nível satisfatório de qualidade.

Os pontos aqui destacados expõem a importância dos fatores avaliados, pois refletem diretamente na efetividade dos serviços. Essas informações devem ser utilizadas pelos gestores locais para aprimorar seus processos de trabalho e garantir a integralidade da atenção à PVHIV nestes serviços. Além disso, a avaliação da qualidade dos serviços especializados permite, ainda, subsidiar a política e planejamento das ações em saúde voltadas para o HIV/Aids.

Deve ser considerado que os resultados obtidos basearam-se em dados secundários, limitando a análise ao especificado no questionário padrão. Uma entrevista com gestores permitiria, além de evidenciar entraves, sugerir ações para minorar os problemas encontrados.

\section{REFERÊNCIAS}

ABIA. Associação Brasileira Interdisciplinar de AIDS. Reunião sobre profilaxia pós-exposição sexual ao HIV. Rio de Janeiro: Abia, 2011.

BACCARINI, R. P. Avaliação de implantação da assistência ambulatorial às PVHA no SUS - Uma análise a partir das pesquisas Qualiaids. 2011. Dissertação (Mestrado em Modalidade Profissional de Saúde Pública) - Escola Nacional de Saúde Pública Sergio Arouca, Rio de Janeiro, 2011.

BRASIL. Lei $n^{\circ} 9.313$, de 13 de novembro de 1996. Dispõe sobre a distribuição gratuita de medicamentos aos portadores do HIV e doentes de AIDS. Brasília, 1996.

BRASIL. Secretaria de Saúde. Programa Nacional de DST e Aids. Diretrizes para o fortalecimento das ações de adesão ao tratamento para pessoas que vivem com HIV e Aids. Brasília, 2007.

BRASIL. Qualiaids - avaliação e monitoramento da qualidade da assistência ambulatorial em Aids no SUS. Brasília, 2008. (Série A - Normas e Manuais Técnicos). 
BRASIL. Ministério da Saúde. Secretaria de Vigilância em Saúde. Departamento de DST, Aids e Hepatites Virais. Protocolo de assistência farmacêutica em DST/HIV/Aids: Recomendações do Grupo de Trabalho de Assistência Farmacêutica. Brasília, 2010. 224 p. (Série A - Normas e Manuais Técnicos).

BRASIL. Ministério da Saúde. Secretaria de Vigilância em Saúde. Departamento de DST, Aids e Hepatites Virais. Caderno de Boas Práticas em HIV/Aids na Atenção Básica. Brasília, 2014.

BRASIL. Ministério da Saúde. Secretaria de Vigilância em Saúde. Departamento de Vigilância, Prevenção e Controle das Infecções Sexualmente Transmissíveis, do HIV/Aids e das Hepatites Virais. Manual Técnico de Elaboração da Cascata de Cuidado Contínuo do HIV. Brasília, DF, 2017. 48 p.

BRASIL. Ministério da Saúde. Protocolo clínico e diretrizes terapêuticas para manejo da infecção pelo HIV em adultos. Brasília: Ministério da Saúde, 2018.

BRASIL. Ministério da Saúde. Departamento de Vigilância. Prevenção e Controle das IST, do HIV/Aids e das Hepatites Virais. 2019a. Disponível em: http://www.aids.gov.br/pt-br. Acesso em: 3 jan. 2019.

BRASIL. Ministério da Saúde. Boletim Epidemiológico de HIV e Aids. Brasília: Ministério da Saúde, 2019b.

CANCIAN, N. R. et al. Importância da atenção multidisciplinar para resgatar o paciente com hiv/aids apresentando baixa adesão à terapia antirretroviral. Rev. de Atenção à Saúde, v. 13, n. 45, p. 55-60, 2015.

COLAÇO, A. D. et al. O cuidado à pessoa que vive com HIV/ AIDS na atenção primária à saúde. Texto \& Contexto - Enfermagem, v. 28, 2019.

IBGE. Instituto Brasileiro de Geografia e Estatística. Disponível em: cidades.ibge.gov/brasil/rs/santa-maria/panorama. Acesso em: 24 set. 2020.

$\mathrm{LOCH}$, A. P. et al. Avaliação dos serviços ambulatoriais de assistência a pessoas vivendo com HIV no Sistema Único de Saúde: estudo comparativo 2007/2010. Cad. Saúde Pública, v. 34, n. 2, p. e00047217, 2018.

MAKSUD, I.; FERNANDES, N. M.; FILGUEIRAS, S. L. Tecnologias de prevenção do HIV e desafios para os serviços de saúde. Revista Brasileira de Epidemiologia, v. 18, supl. 1, p. 104-119, 2015.

MAGNABOSCO, G. T. et al. Assistência ao HIV/aids: análise da integração de ações e serviços de saúde. Esc. Anna Nery, v. 22, n .4, p. 1-7, 2018.

MELCHIOR, R. et al. Avaliação da estrutura organizacional da assistência ambulatorial em HIV/Aids no Brasil. Revista de Saúde Pública, São Paulo, v. 40, n. 1, p. 142-151, 2006.

MEDEIROS L.B. et al. Integração entre serviços de saúde no cuidado às pessoas vivendo com aids: uma abordagem utilizando árvore de decisão. Ciênc. Saúde Colet., v. 21, n. 2, p. 543-552, 2016.

MENEZES, P. D. L. et al. Grau de adesão à terapia tripla combinada antirretroviral em pacientes diagnosticados com HIV/AIDS no Serviço de Atendimento Especializado. Rev. Mult. Psic., v. 13, n. 44, p. 811-827, 2019.
NEMES, M. I. B. et al. Avaliação da qualidade da assistência no programa de AIDS: questões para a investigação em serviços de saúde no Brasil. Cadernos de Saúde Pública, v. 20, n. suppl 2, p. S310-S321, 2004.

NEMES, M. I. B. et al. Avaliação de serviços de saúde: a experiência do Qualiaids. In: AKERMAN, M.; FURTADO, J. P. (org.). Práticas de avaliação em saúde no Brasil: diálogos. p. 99-151, 2015. Cap. 3.

NEMES M. I. B. Nota sobre utilização de resultados do Questionário Qualiaids em todos os tipos de publicações (apresentações; notas técnicas, relatórios, oficinas de trabalho, artigos em revistas, capítulos de livro, etc.). 2017. Disponível em: http://www.qualiaids.fm.usp.br/aplicacao.html.

PINKERTON, S. D.; HOLTGRAVE, D. R.; GALLETLY, C. L. Infections prevented by increasing HIV serostatus awareness in the United States, 2001 to 2004. Journal of Acquired Immune Deficiency Syndromes, v. 47, n. 3, p. 354-357, 2008.

RODRIGUES V. P. V. et al. Impacto do atendimento farmacêutico individualizado na resposta terapêutica ao tratamento antirretroviral de pacientes HIV positivos. Journal of Applied Pharmaceutical Sciences - JAPHAC, v. 1, p. 18-28, 2015.

SOUZA, B. M. B. et al. A política de AIDS no Brasil: uma abordagem histórica. Journal of Management and Primary Health Care, v. 1, n. 1, p. 23-26, 2010.

USP. Universidade de São Paulo. Qualiaids. São Paulo. 2019. Disponível em: http://www.qualiaids.fm.usp.br/index.html. Acesso em: 30 jan. 2020. 